\title{
Effect of banded carbide structure on the rolling contact fatigue of GCr15 bearing steel
}

\author{
Ming $\mathrm{Li}^{\mathrm{a}}$, Henghua Zhang ${ }^{\mathrm{b}}$
}

(State Key Laboratory of Advanced Special Steel,Shanghai Key Laboratory of Advanced Ferrometallurgy, School of Materials Science and Engineering, Shanghai University, Shanghai 200072,China)

amingyuw@163.com, bhhzhang@shu.edu.cn

* Corresponding author: Henghua Zhang

\begin{abstract}
In this paper, the influence of banded carbide structure on Rolling Contact Fatigue (RCF) of GCr15 bearing steel was investigated by using MMS-2A double-roller wear tester under dry friction at room temperature. Surface damage was characterized using SEM and OM. The results showed that with the increase of banded carbide grade, wear rate and friction coefficient were obviously increased and contact fatigue performance was deteriorated. For the high grade of banded carbide, the main failure form is fatigue pits and surface cracks. On the contrary, for the low grade of banded carbide, the main failure form is flaking off. Besides, with the increment of banded carbide grade, the thickness of plastic deformation layer increase. The fatigue cracks easy propagated in the plastic deformation layer along the rolling direction. Therefore, by reducing the banded carbide grade can effectively improve the rolling contact fatigue properties of bearing steel.
\end{abstract}

Key words: GCr15 bearing steel; banded carbide; RCF

\section{Introduction}

Bearing balls and rolling-element bearings experience subsurface initiated fatigue failures due to RCF.The bearings used in practical applications are designed to operate at nominal stress levels well below the yield strengths of the materials. However, the presence of imperfections and non-metallic inclusions introduces heterogeneity at the microstructural level[1]. With increasing in number of cycles, the ratcheting strain accrues, and therefore it can serve as a meaningful parameter to quantify the evolution of a material damage due to RCF[2,3].Once this damage reaches a critical value, a fatigue crack nucleates in the subsurface of a material. Since this local plastic strain accumulation takes place in the vicinity of carbides, it is important to understand their role towards ratcheting under RCF loading conditions.

Generally, the influence factors of RCF failure of bearing steel is non-metallic inclusion, distribution of carbide and purity of steel. Undoubtedly, previous studies have showed the RCF would reduce the life and reliability of many useful components, such as gears, rolling bearings[4-6]. Nagao $M$ find the stiffness of an inclusion and its location have a significant effect on the RCF life, stiffer inclusions and inclusions located the depth of maximum shear stress reversal are more detrimental to the RCF life[7].T.Karsch studied the effects of hydrogen content and microstructure on fatigue behavior of steel GCr15 in the VHCF regime[8], and it is found that increased hydrogen content in bearing steel at 5 ppm (by weight) will significantly promote bearing spalling failure[9,10]. Shigeo shmizu's studies show that the bearing fatigue life is directly related to the instantaneous contact time, with the increase of the instantaneous contact time, the fatigue life is also increased[11]. O.P.Datsyshyn introduced the mechanism of fatigue crack propagation in metallic materials[12]. G.John put forward the using of bearing steel under normal conditions, due 
to the surface material subjected to repeated contact stress, the surface or sub-surface initiation cracks, and ultimately lead to fatigue failure of rolling bearings[13].

The heterogeneity of carbide in bearing steel has an important influence on RCF performance [14]. This paper mainly introduced the influence mechanism of banded carbide. The GCr15 bearing steel was treated by different heat treatment to obtain 1 grade, 2.5 grade, 4 grade banded carbide, using MMS-2A wear tester to study the rolling contact fatigue. Via the experiment analyze of material science and metallography, the bearing steel of banded carbide lead to fatigue crack and propagation mechanism was researched. In addition, the relationship between wear rate, friction coefficient and the banded carbide grade was discussed.

\section{Experimental}

\subsection{Specimen preparation}

The material used in this study was the GCr15 bearing steel, which is a type of steel widely used in the manufacture of several types of rolling-element bearings. Tested steel is a commercially bar with a diameter of $45 \mathrm{~mm}$. The chemical composition (wt.\%) of the GCr15 bearing steel is shown in Table 1.

Table 1 Chemical composition of the experiment steel (wt.\%)

\begin{tabular}{ccccccccc}
\hline $\mathrm{C}$ & $\mathrm{Si}$ & $\mathrm{Mn}$ & $\mathrm{P}$ & $\mathrm{S}$ & $\mathrm{Cr}$ & $\mathrm{Mo}$ & $\mathrm{Ni}$ & $\mathrm{Al}$ \\
\hline 1.02 & 0.247 & 0.38 & 0.012 & 0.0050 & 1.46 & 0.0132 & 0.035 & 0.022 \\
\hline
\end{tabular}

\subsection{The RCF test}

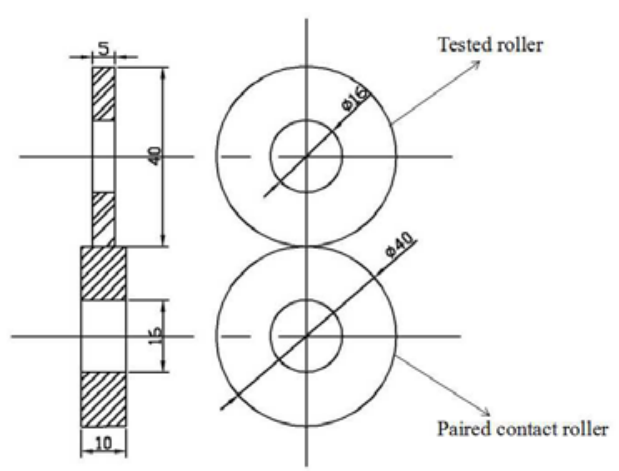

Fig.1 Schematic of the double-roller RCF test rig

A MMS-2A tribometer was used to evaluate the RCF performance was shown in Fig.1.The speed of the tested ring was kept as a constant value of $400 \mathrm{rpm}$. The paired contact roller was SDC99 cold die steel, average surface roughness was $0.031 \mu \mathrm{m}$, and a Rockwell hardness was 63 HRC. All the RCF test were conducted under dry friction condition. The maximum contact stress $\left(\sigma_{\max }\right)$ was $134 \mathrm{Mpa}$, which calculated using Hertz's equation. After every test, the old paired contact roller was replaced by a new one.

\section{Results and discussion}

\subsection{Matrix structure of different banded carbide grade}

In order to obtain different banded carbide grade, the GCr15 bearing steel was treated by different heat treatment. Table 2 gives the particular heat treatment parameters of three different banded carbide grades. After spheroidizing annealing, furnace cooling to $650^{\circ} \mathrm{C}$, then air cooling to $600^{\circ} \mathrm{C}$ and water quenching. In this study, the surface roughness of the sample was measured by the TR200 roughness tester, the hardness was measured by hardness tester. Before and after the experiment, acetone was used to clean the samples for $10 \mathrm{~min}$ and dried. The wear mass of the 
sample was weighed by 1/1000 electronic balance. The SEM studies were conducted on a HITACHI SU-1500 equipped with EDS and an INCA software.

Table 2 The heat treatment parameters of GCr15 bearing steel with different banded carbide grade

\begin{tabular}{cccccc}
\hline $\begin{array}{c}\text { Sample } \\
\text { No. }\end{array}$ & $\begin{array}{c}\text { Austenitizing } \\
\text { temperature and } \\
\text { holding time }\end{array}$ & $\begin{array}{c}\text { Normalizing } \\
\text { temperature and } \\
\text { holding time }\end{array}$ & $\begin{array}{c}\text { Annealing } \\
\text { temperature and } \\
\text { holding time }\end{array}$ & $\begin{array}{c}\text { Quenching } \\
\text { and } \\
\text { tempering }\end{array}$ & $\begin{array}{c}\text { carbon } \\
\text { banded } \\
\text { grade }\end{array}$ \\
\hline $1 \#$ & & $1000^{\circ} \mathrm{C} \times 2 \mathrm{~h}$ & $760^{\circ} \mathrm{C} \times 4 \mathrm{~h}$ & $850^{\circ} \mathrm{C}$ & 1 \\
$2 \#$ & $850^{\circ} \mathrm{C} \times 2 \mathrm{~h}$ & $980^{\circ} \mathrm{C} \times 2 \mathrm{~h}$ & $750^{\circ} \mathrm{C} \times 2 \mathrm{~h}$ & $+150^{\circ} \mathrm{C}$ & 2.5 \\
$3 \#$ & & $/$ & $760^{\circ} \mathrm{C} \times 4 \mathrm{~h}$ & & 4 \\
\hline
\end{tabular}

The grade of banded carbide was assessed according to the standard of GB/T 18254-2002 in the longitudinal of the quenched specimens, was shown in Fig.2.The microstructure of GCr15 bearing steel etched deeply by $4 \%$ Nitric acid alcohol. The white area is the banded carbide structure, dark area is the matrix microstructure of martensite.
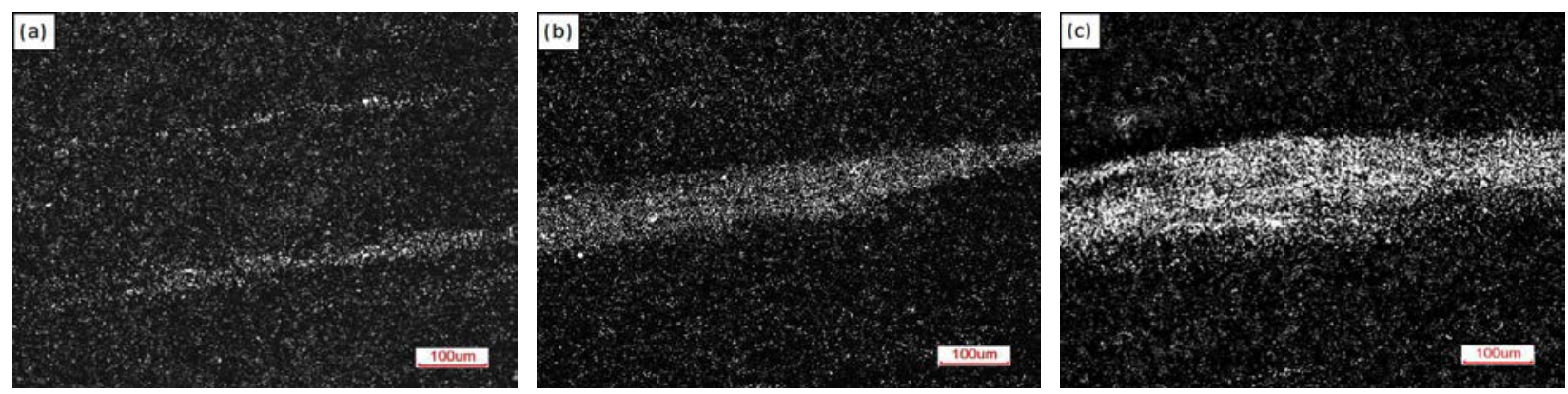

Fig.2 Distribution of carbides after quenching with different banded carbide grade of GCr15 bearing steel : (a) grade 1;(b) grade 2.5;(c) grade 4

\subsection{Fatigue wear}

As the hardness and surface roughness have great influence on wear resistance. In order to study the influence of banded carbon on wear resistance accuratly, the differences of microhardness was analyzed first. Due to the aggregation of the alloy elements in the banded carbon area, the contents of $\mathrm{Cr}$ and $\mathrm{Mn}$ metal elements sharply increased[15], the hardness of the $\mathrm{Cr}$ and $\mathrm{Mn}$ rich area is higher than the matrix area about $20-50 \mathrm{HV}$, as shown in Table 3.

Table 3 Mechanical properties of GCr15 bearing steel with different banded carbide grade

\begin{tabular}{cccccc}
\hline \multirow{2}{*}{$\begin{array}{c}\text { Sample } \\
\text { No. }\end{array}$} & \multicolumn{2}{c}{ Micro-hardness/HV } & Roughness \\
\cline { 2 - 3 } & banded carbon areas & matrix & $\begin{array}{c}\text { average wear rate } \\
10^{-8} \mathrm{~g} / \mathrm{N} \cdot \text { cycle }\end{array}$ & $\begin{array}{c}\text { friction } \\
\text { coefficient }\end{array}$ \\
\hline $1 \#$ & 800 & 774 & 0.441 & 5.43 & 0.75 \\
$2 \#$ & 790 & 746 & 0.403 & 5.80 & 0.63 \\
$3 \#$ & 810 & 757 & 0.425 & 6.41 & 0.52 \\
\hline
\end{tabular}

Wear rate is an essential parameter to evaluate the anti-wear properties of bearing steel. The experimental results indicate that the wear rate of materials is affected by the banded carbide grade.Fig. 3 shows that the wear rate changes with the banded carbide grade. When the banded carbide reach to grade 4, the wear rate is higher than others grade because the hardness distributed unevenly, and carbide belongs to brittle phase. In the process of RCF wear, the carbide is easy to fall off to produce flaky off, so the wear loss changes quickly. Compared with grade 1, the wear rate of the banded carbide of grade 2.5 increased by $6.8 \%$, and that of grade 4 increased by $18 \%$. 


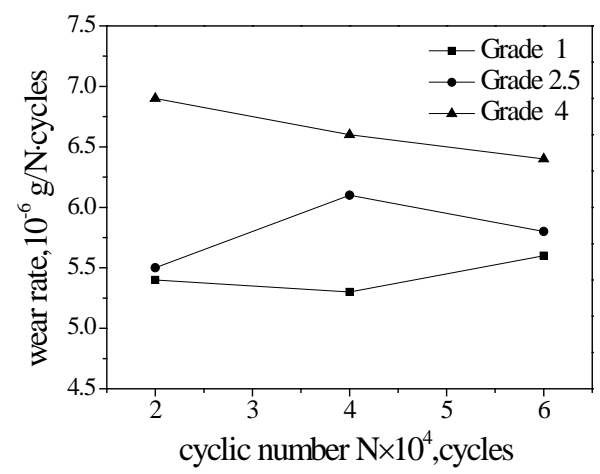

Fig .3 Wear rate of GCr15 bearing steel changes with different banded carbide grade

Fig.4 shows the relationship between the friction coefficient changes and the banded carbide grade of GCr15 bearing steel. The result shows that in the double-roller RCF test, the friction coefficient of all samples becomes more and more stable, and the wear loss increases with increasing time. There is a good relationship between friction coefficient and banded carbide grade, the lower banded carbide grade is, the smaller the friction coefficient is. Under the same load and test duration, compared with grade 4 and grade 1, the friction coefficient is reduced by $29.7 \%$.The change of the friction coefficient can reasonably explain the change of wear rate.

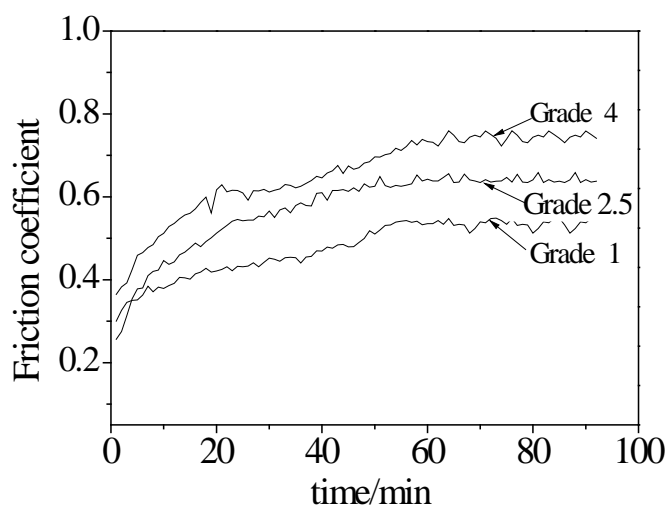

Fig.4 The friction coefficient of GCr15 bearing steel changes with the banded carbide grade

\subsection{RCF failure observations and mechanism analysis}

The RCF test results indicated that three grades of banded carbide have different failure modes: the abrasion, abrasive wear, spalling, surface crack and fatigue pit. These failure modes were obviously different and easily distinguished. Fig.5(a) shows the overall morphology of the surface fatigue wear when the banded carbide grade is 1 . The peeling area is relatively small, such as the rectangular area 1, where no significant cracks observed in Fig.5(b).
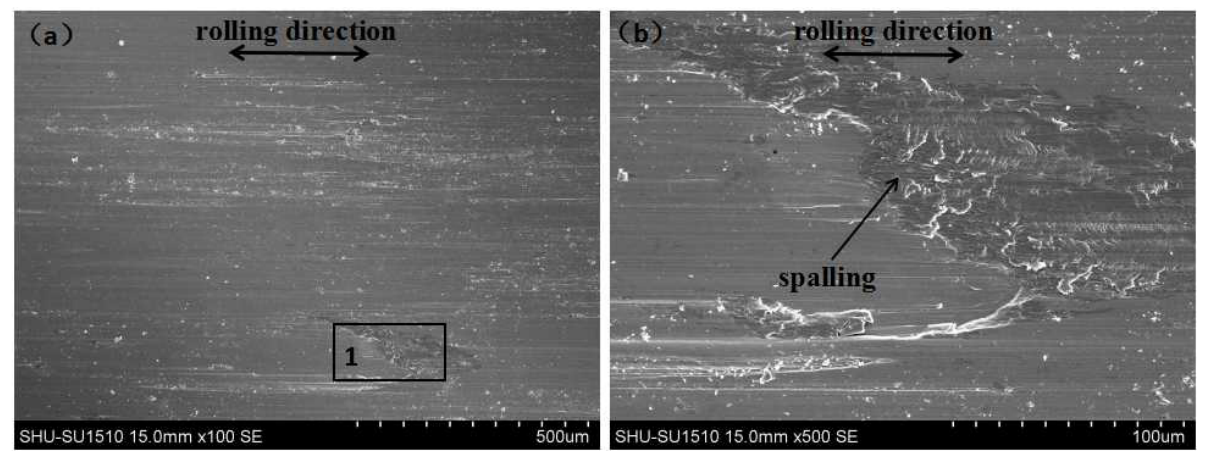

Fig.5 Wear morphology of GCr15 bearing steel with banded carbide grade 1: (a)overall view;

(b)typical RCF morphology of small spalling areas( $\mathrm{N}=6 \times 10^{4}$ cycles)

Fig.6 (a) shows the overall morphology of the surface fatigue wear when the banded carbide 
grade is 2.5. In order to analyze the microstructure of region1, as shown in Fig.6(b).Fig.6(c) shows a high magnification SEM micrograph of the loose and porous, was enlarged of region 2, where easily to produce abrasive debris and become to be a spalling pit. Fig.6(d) was enlarged of region 3, which displays a typical surface crack morphology under SEM. The crack spreaded on the surface, which is the typical feature of fatigue crack propagation, the length of surface cracks reach to

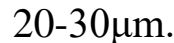
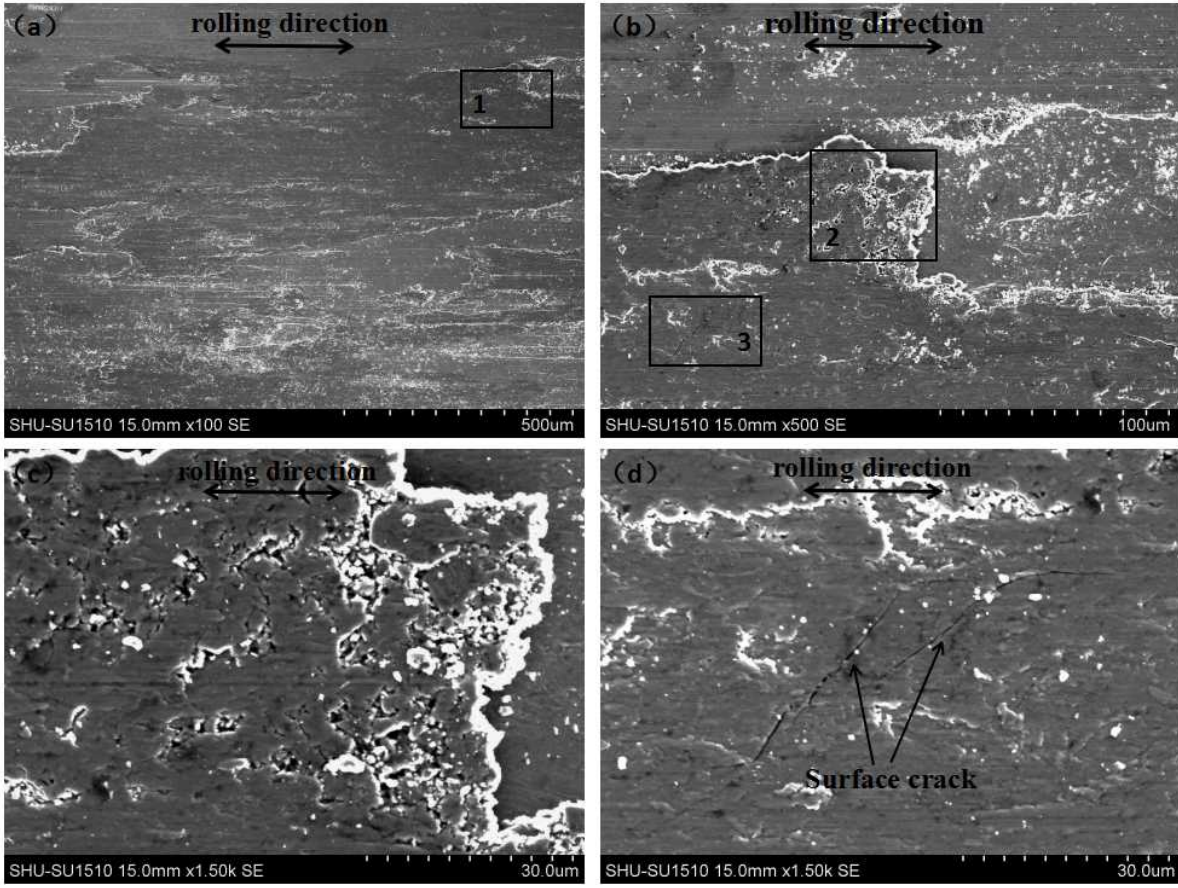

Fig.6 Wear morphology of GCr15 bearing steel with banded carbide grade 2.5: (a)overall view;(b) enlarged of region 1;(c) enlarged of region 2 of pores; (d) enlarged of region 3 of surface crack $\left(\mathrm{N}=6 \times 10^{4}\right.$ cycles $)$
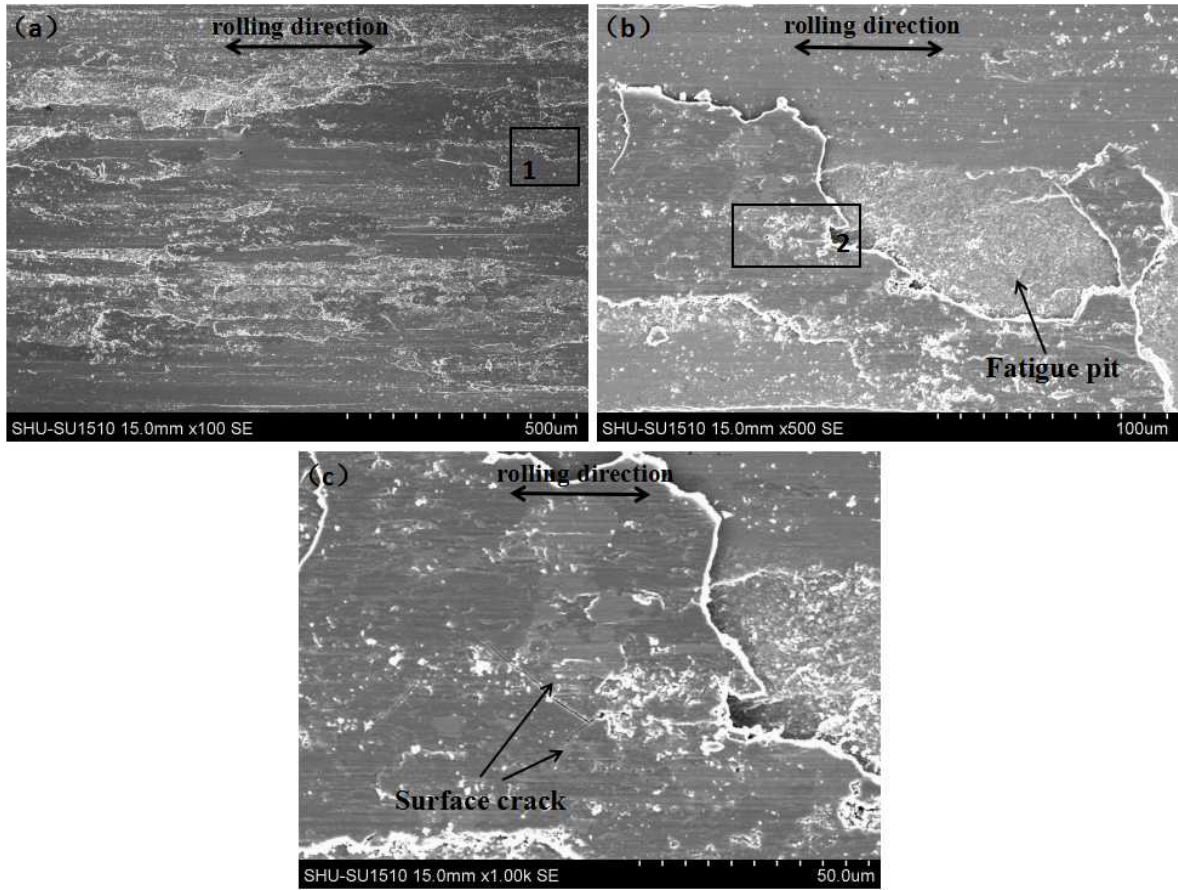

Fig.7 Wear morphology of GCr15 bearing steel with banded carbide grade 4 : (a) overall view;(b) enlarged of region 1 with fatigue pit and delamination;(c) enlarged of region 2 with surface crack and sharply spalling crack $\left(\mathrm{N}=6 \times 10^{4}\right.$ cycles $)$ 

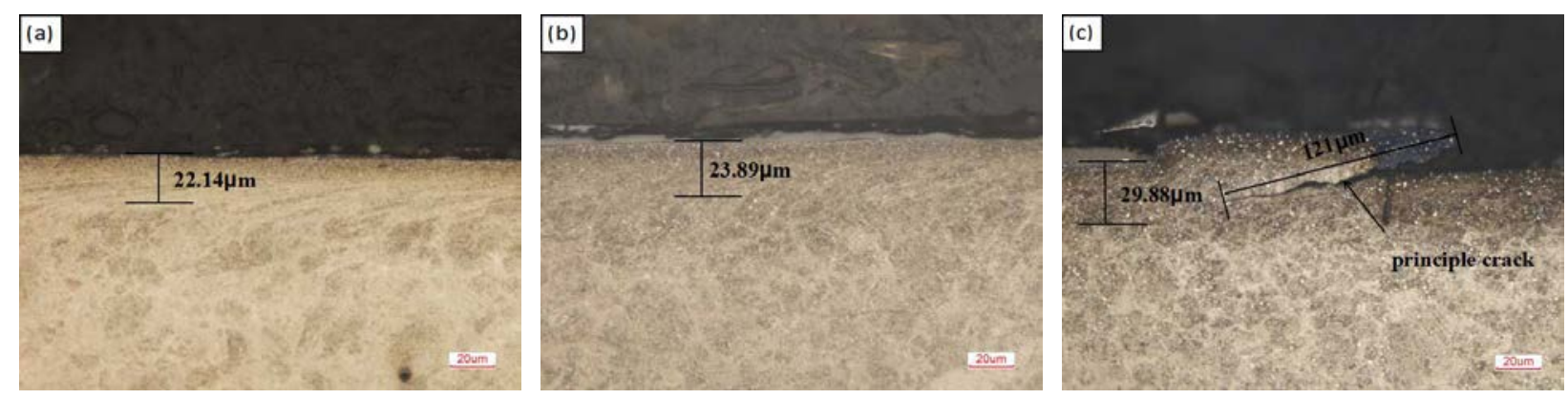

Fig.8 The surface and cross-section micro-graph of samples after RCF test: (a) grade 1;(b) grade

\section{5;(c) grade 4}

Fig.7 shows the surface fatigue wear morphology of the banded carbide grade 4.During the experiment, it can be found that when the banded carbide grade is high, the surface of the specimen spalling phenomenon is more serious and visible to be see of naked eye easily. Fig.7 (a) for the overall morphology of the sample, there are also have a large number of pits with shallow depth, and heavy adhesive. Fig.7(b)shows the enlargement of the rectangular region 1, surface fatigue cracks cause obvious peeling phenomenon. Fig.7(c) shows the enlargement of the rectangular region 2, the surface cracks were visible, the length of them is about $10-25 \mu \mathrm{m}$. These areas continue to expand and fall off to form spalling pits and wear debirs[16].

Fig.8 shows the plastic deformation layer thickness changes with the banded carbide grade. It is caused by friction of the contact surface, the surface material flows in the direction of friction. The plastic deformation layer become thicker with the increase of banded carbide grade. Re-tempering has occurred in the course of the experiment, the carbides segregate along the crystal defects and diffuse out. The banded carbide structure of grade 4, carbide particles of fatigue layer is relatively large than the matrix. As we know, the carbides of martensite reduced, the hardness is reduced too. The sample easy to out of shape, and it also can explain the increase of wear loss. Fatigue cracks initiate from the wear surface and grow along with the soft ferrite lines within the plastically deformed layer [17].

In this experiment, the fatigue cracks easy propagated in the plastic deformation layer of carbide concentration area along the rolling direction, and finally forming a fatigue pit. The wear surface of Fig.8 (a) is smoothly, have no obvious spalling, crack ,and others micro-defects. Fig.8 (b), the surface is relatively rough; Fig.8(c) shows the longitudinal crack, which the debris comes from the outermost layer of plastic deformation where the microstructure is severely deformed. Presumably, granular carbides induce the crack nucleation in the subsurface, and the cracks propagate towards the surface to form fatigue spalling.

Through the comparison of the fatigue surface and cross-section morphologies, we can find that the higher the banded carbide grade, the more obvious of spalling and crack is, the sharp surface crack become the main failure mode. As failure modes changed from the abrasion, spalling to rolling cracking, the degree of failure is more and more serious. The existence of surface fatigue cracks lead to the spalling, and wear loss increased. Generally, the spalling failure originated from the unstable surface crack. The banded carbide in bearing steel rolling is eutectic carbide broken to the microstructure distribution along the rolling, with the increase of banded carbide grade, the thermal sensitivity also increased when quenching. The hardness difference between the banded carbides and the matrix, is the sources of surface crack to shorten the fatigue life.

\section{Conclusions}

This paper comparatively studied on the influence of the banded carbide on the RCF failure. On 
the basis of section 3, it can be concluded that:

1) It can be seen from $1 \#$ and $3 \#$ samples that the normalizing process can reduce the banded carbide grade. The wear rate and friction coefficient decrease significantly with the increment of banded carbide grade. Compared with grade 1,the wear rate of the banded carbide of grade 2.5 increased by $6.8 \%$, and that of grade 4 increased by $18 \%$.

2) The image of fatigue spalling results indicated that the fatigue performance was directly influenced by the exist of banded carbide structure. For the high grade of banded carbide, the main failure form was spalling, fatigue pits and surface cracks. On the contrary, for the low grade of banded carbide, the main failure form was abrasion and small area of spalling.

3) The plastic deformation layer was more obvious when the banded carbide grade was high, the fatigue cracks easy propagated in the plastic deformation layer. In a word, reducing the banded carbide grade can improve the RCF properties of GCr15 bearing steel.

\section{References}

[1] Anup S.Pandkar,Nagaraj Arakere,Ghatu Subhash. Microstructure-sensitive accumulation of plastic strain due to ratcheting in bearing steels subject to Rolling Contact Fatigue[J]. International Journal of Fatigue , 2014,63:191-202

[2] Ringsberg J W. Cyclic ratchetting and failure of a pearlitic rail steel[J]. Fatigue \& Fracture of Engineering Materials \& Structures, 2000, 23(9):747-758.

[3] Alley ES,Neu RW. Microstructure-sensetive modeling of rolling contact fatigue.Int J Fatigue.2010;32:841-850

[4] Beghini M, Santus C. An application of the weight function technique to inclined surface cracks under rolling contact fatigue, assessment and parametric analysis[J].Engineering Fracture Mechanics, 2013, 98(98):153-168.

[5] Upadhyay R K, Kumaraswamidhas L A, Azam M S. Rolling element bearing failure analysis: A case study[J]. Case Studies in Engineering Failure Analysis, 2013, 1(1):15-17.

[6] P.C.Becker, Microstructural changes around non-metallic inclusions caused by rolling contact fatigue in ball bearing, Met. Technol. 2013,8:234-243.

[7] Nagao M,Hiraoka K,Unigame Y. Influence of non-metallic inclusion size on rolling contact fatigue life in bearing steel[J].Sanyo Technical Report, 2005,12(1): 38-45

[8] T.Karsch ,H.Bomas ,H.-W.Zoch. Influence of hydrogen content and microstructure on the fatigue behaviour of steel SAE 52100 in the VHCF regime. International Journal of Fatigue.2014:74-89

[9] Vegter R H, Slycke J T. The role of hydrogen on rolling contact fatigue response of rolling element bearings[J]. Journal of ASTM international, 2009, 7(2): 1-12.

[10] Uyama H, Yamada H, Hidaka H, et al. The effects of hydrogen on microstructural change and surface originated flaking in rolling contact fatigue[J].Tribology Online, 2011, 6(2): 123-132.

[11]Shigeo shmizu.Fatigue Limit Concept and Life Prediction Model for Rolling Contact Machine Elements[J].Trbio.Trans.,2002,45(1):39-46

[12]Datsyshyn O P,Panasyuk V V.Pitting of the rolling bodies contact surface[J]. Wear,2001, 251(1-12):1347-1355.

[13]G.John, E.Darlene, C.Shelton.Accurate Assessment of Partical Counts in Liquids. Lubrication Engineering.1995, 51 (3):205 208

[14]Bhadeshia H.K.D.H. Steels for bearings[J].Progress in Materials Science, 2012, 57(2): 268-435.

[15]Majka T F, Matlock D K, Krauss G. Development of microstructural banding in low-alloy steel 
with simulated Mn segregation[J]. Metallurgical and Materials Transactions A, 2002, 33(6):1627-1637.

[16]Rycerz P, Olver A, Kadiric A. Propagation of surface initiated rolling contact fatigue cracks in bearing steel[J]. International Journal of Fatigue, 2017, 97: 29-38.

[17]He C G, Guo J, Liu Q Y, et al. Experimental investigation on the effect of operating speeds on wear and rolling contact fatigue damage of wheel materials[J]. Wear, 2016, 364: 257-269. 